\title{
DAMPAK PERUBAHAN PSAK TERHADAP KOMPETENSI DOSEN DAN TINGKAT PEMAHAMAN MAHASISWA DI PRODI AKUNTANSI UNIVERSITAS MUHAMMADIYAH SIDOARJO
}

\author{
Duwi Rahayu ${ }^{1}$ Imelda Dian Rahmawati ${ }^{2}$, Bayu Hari Prasojo ${ }^{3}$ \\ Universitas Muhammadiyah Sidoarjo
}

\begin{abstract}
The purpose of this study was to determine the impact of changes in PSAK on the competence of lecturers and the level of understanding of students in the Accounting Study Program, University of Muhammadiyah Sidoarjo. The impact of changes in PSAK should be balanced with an increase in the ability of accounting lecturers in higher education to support learning materials that are in sync with the world of work, so an increase in lecturer competence is needed. Furthermore, the level of understanding of accounting students also needs to be updated, to support increased knowledge of standard changes, namely the latest PSAK, amended PSAK and revised PSAK. This research is a quantitative study. The method used in data collected in this study is distributing questionnaires that are processed using SmartPLS 3. The data that can be obtained are 100 respondents. The results of this study are the impact of changes in PSAK affects the competence of lecturers, and the impact of changes in PSAK also affect the level of understanding of students.
\end{abstract}

Keywords

Correspondence to
: Impact of PSAK changes; competency of lecturers; level of understanding of students

:duwirahayu@umsida.ac.id

\section{ABSTRAK}

Tujuan penelitian ini adalah untuk mengetahui dampak perubahan PSAK terhadap kompetensi dosen dan tingkat pemahaman mahasiswa Program Studi Akuntansi Universitas Muhammadiyah Sidoarjo. Dampak perubahan PSAK hendaknya diimbangi dengan peningkatan kemampuan dosen akuntansi di perguruan tinggi dalam mendukung materi pembelajaran yang sinkron dengan dunia kerja, sehingga diperlukan peningkatan kompetensi dosen. Selanjutnya tingkat pemahaman mahasiswa akuntansi juga perlu diperbarui, untuk mendukung peningkatan pengetahuan tentang perubahan standar yaitu PSAK terbaru, PSAK amandemen dan PSAK revisi. Penelitian ini merupakan penelitian kuantitatif. Metode yang digunakan dalam pengumpulan data dalam penelitian ini adalah dengan menyebarkan kuesioner yang diolah menggunakan SmartPLS3. Data yang dapat diperoleh sebanyak 100 responden. Hasil penelitian ini adalah dampak perubahan PSAK berpengaruh terhadap kompetensi dosen, dan dampak perubahan PSAK juga berpengaruh terhadap tingkat pemahaman mahasiswa.

Kata Kunci : Dampak perubahan PSAK; kompetensi dosen; tingkat pemahaman siswa

\section{Riwayat Artikel:}

Received : 23 Mei 2020

Revised : 26 November 2020

Accepted: 11 Januari 2021 


\section{PENDAHULUAN}

Dampak perubahan standar diawali dengan proses konvergensi. Menurut Mahendra (2013), makna konvergensi adalah kondisi berpusat satu titik yang bertemu. Sehingga konvergensi IFRS bisa dimaknai sebagai PSAK yang akan diarahkan pada satu titik dengan international financial reporting standard.

Menurut Dwi Martani (2019) Dampak perubahan standar yang berbasis IFRS dapat diakibatkan oleh perubahan suatu standar yakni pertama recognition (pengakuan), measurement (pengukuran), presentation (penyajian) atau disclosure (pengungkapan). Kedua kesesuaian standar terhadap transaksi dan penyajian financial statements perusahaan. Ketiga Pengungkapan financial statements sebelum periode perubahan dilakukan yakni Catatan atas financial statements yang terdiri dari Kebijakan akuntansi yang telah efektif dan Dampak perubahan kebijakan akuntansi apabila diimplementasikan. Dampak yang keempat Penyajian financial statements pada periode perubahan dilakukan yakni a. Penyajian kembali financial statements; Statement of financial position menggunakan kebijakan akuntansi yang baru, dan Profit and loss menggunakan kebijakan akuntansi yang baru, b. Kebijakan akuntansi dengan menggunakan kebijakan akuntansi baru, c. Notes to financial statements khusus mendeskripsikan perubahan suatu kebijakan dan Restatement value, d. Adanya deskripsi terkait akun yang mendapatkan pengaruh atas perubahan standar berbasis IFRS.

Menurut Saretta (2019) Statement of Financial Accounting Standards or PSAK is a reference procedure framework in preparing accounting financial reports. PSAK contains rules relating to the activities of recording, preparing, conducting and presenting a financial report. Sedangkan menurut Efritania (2014) PSAK adalah standar dalam melaksanakan kegiatan terkait akuntansi yang didalamnya memuat seluruh aspek yang berhubungan dengan akuntansi, yang disusun oleh Ikatan Akuntan Indonesia (IAI).
Menurut Ersa Tri Wahyuni (2020) Berikut dampak perubahan SAK (standar akuntansi keuangan) di tahun 2020 : a. PSAK terbaru yang efektif di tahun 2020 ini yakni PSAK 72 Pendapatan dari kontrak dengan pelanggan b. Draf Eksposure terkait penghitungan atas pendapatan kontrak asuransi (PSAK 74), c. ISAK terbaru, tentang ketidakpastikan pajak (ISAK 34).

Wahyuni (2009) menyatakan bahwa dampak dari perubahan standar yaitu perubahan pada berbagai referensi akuntansi dan PSAK yang dijadikan sebagai bahan ajar di perguruan tinggi di Indonesia. Sehingga dosen-dosen akuntansi wajib mempelajari kembali tentang ketentuan dan peraturan yang terbaru dan meningkatkan kompetensinya seiring dengan banyaknya dampak perubahan dalam standar akuntansi serta harus siap atas segala perubahan PSAK ke depannya.

Kompetensi adalah campuran knowledge, behavior, serta expertise yang bisa diperoleh lecturer untuk dapat mencapai tujuan atas pembelajaran. Kompetensi merupakan keahlian untuk menjalankan kewajiban yang dilengkapi dengan keterampilan (Wibowo, 2007). Maknanya seiring dengan perkembangan perubahan PSAK, maka dosen berkewajiban memiliki kompetensi yang memadai terkait PSAK terbaru, amandemen, eksposure maupun ISAK yang terbaru dengan tujuan untuk memberikan kontribusi yang bermanfaat serta sebagai sumber pengetahuan ilmu di bidang akuntansi.

Utami (2012) dalam Gustiani dan Marsudi (2018) menjelaskan bahwa kompetensi adalah kemampuan yang dimiliki masing-masing individu, dimana seseorang telah mampu memahami dan melakukan suatu kewajiban serta mampu melakukan analisis pekerjaan dan aturan-aturan dalam pekerjaan.

Martinis (2006) menyatakan bahwa Berdasarkan UU No 14 tahun 2005 yang menjelaskan "Kompetensi dosen terdiri dari Pedagogical competence, personality competence, social competence, and professional competence". Dosen yang memiliki kompetensi amat dicari dalam kondisi perkembangan dunia pendidikan yang semakin maju. 
Christiani (2015) menyampaikan pemahaman adalah kapasitas manusia dalam memahami sesuatu setelah banyak dilihat dan dikenali. Tingkat Pemahaman PSAK berbasis IFRS merupakan tingkat kemahiran seseorang dengan tujuan untuk mengingat, dan memahami peraturan yang berlaku pada PSAK berbasis IFRS.

Level pemahaman akuntansi mahasiswa dideskripsikan dengan sampai dimana seseorang dapat memahami terhadap apa yang telah dipelajari oleh mahasiswa terkait mata kuliah akuntansi, bukan hanya dinyatakan dari value yang diperoleh dalam pembelajaran tetapi juga mahasiswa tersebut mampu memahami konsep-konsep perubahan standar akuntansi (Budhiyanto dan Nugroho, 2004).Tingkat atau level pemahaman perubahan standar dilihat dari sampai dimana mahasiswa dapat memahami dan menjelasakan tentang perubahan standar. Tingkat atau level Pemahaman IFRS terdiri dari pemahaman awal dan pemahaman IFRS secara komprehensif.

Menurut Kieso (2007) Tingkat pemahaman mahasiswa akuntansi meliputi suatu kemampuan dalam melakukan: The recording stage, the classification stage, the summarization stage, the reporting stage, and the analysis stage. Pemahaman atas akuntansi merupakan suatu keahlian seseorang dalam mengetahui dan memahami akuntansi (Nandakumar, 2012).

Ketika tingkat pemahaman mahasiswa akuntansi sudah dikatakan baik, maka diharapkan mahasiswa dapat peka dengan perubahan standar yang ada, agar ketika lulus nantinya mereka dapat memberikan kontribusinya bagi perusahaan atau institusi tempat bekerja mereka nanti, karena mayoritas perusahaan dan pelaku sektor keuangan banyak yang sudah menerapkan dan mengikuti perubahan PSAK.

Pada penelitian sebelumnya Heykal et al (2014), Poudel et al (2014) dan Nurunnabi (2014) menyatakan bahwa dampak perubahan standar ternyata berpengaruh terhadap sektor pendidikan dalam hal ini adalah kompetensi dosen dan tingkat pemahaman mahasiswa. Dimana level (tingkat) pendidikan juga mempengaruhi proses perkembangannya. Hal serupa juga dinyatakan oleh Zeghal dan Mhedhbi (2006) bahwa dengan adanya perubahan standar seharusnya menjadi perhatian lebih bagi para mahasiswa akuntansi dan akuntan pendidik (dosen). Hal tersebut dilakukan dengan tujuan untuk mendukung materi pembelajaran yang singkron dengan dunia kerja dan juga untuk mendukung peningkatan pengetahuan mengenai perubahan standar yakni PSAK terbaru, PSAK amandemen dan PSAK revisi.

Hal serupa juga dinyatakan Bastian (2011) yang mengungkapkan bahwa perubahan standar memberikan pengaruh besar pada perkembangan akuntansi di berbagai negara meliputi praktik di berbargai sektor salah satunya adalah dunia pendidikan. Sedangkan Pulungan (2013) juga menyatakan Dampak perubahan PSAK merupakan tantangan dalam dunia akademik dan memberikan pengaruh terhadap peningkatan kompetensi dosen dan tingkat pemahaman mahasiswa akuntansi di Indonesia. Berdasarkan latar belakang diatas, penulis menyusun hipotesis berikut ini :

H1 Dampak Perubahan PSAK berpengaruh terhadap Kompetensi Dosen di Prodi Akuntansi Universitas Muhammadiyah Sidoarjo

H2 Dampak Perubahan PSAK berpengaruh terhadap Tingkat Pemahaman Mahasiswa di Prodi Akuntansi Universitas Muhammadiyah Sidoarjo

\section{METODE PENELITIAN}

Penelitian ini merupakan penelitian kuantitatif, populasi penelitian ini adalah mahasiswa prodi akuntansi Universitas Muhammadiyah Sidoarjo. Sampel penelitian ini didapat dengan kriteria yaitu mahasiswa berstatus aktif dan masih atau sudah menempuh mata kuliah akuntansi keuangan menengah. Teknik pemilihan sampel menggunakan purposive sampling, Menurut Sugiyono (2013) Pengujian Instrumen didasarkan pada data penelitian berupa kuesioner, kemudian data bisa diolah dengan menggunakan skala pengukuran likert. Setiap respon dari instrument indicators yang menerapkan skala pengukuran likert memiliki tingkatan dari value yang paling tinggi hingga 
yang paling bawah. Berikut opsi respon atau jawaban yang dapat dipilih oleh para responden:

TABEL 1: Opsi Jawaban Responden

\begin{tabular}{cl}
\hline Skala & \multicolumn{1}{c}{ Interpretasi } \\
\hline 1 & Sangat Tidak Setuju \\
\hline 2 & Tidak Setuju \\
\hline 3 & Kurang Setuju \\
\hline 4 & Setuju \\
\hline 5 & sangat Setuju
\end{tabular}

Sumber: Sugiyono (2013)

\section{HASIL PENELITIAN}

Penelitian ini memakai data primer yang diperoleh dari pendistribusian kuisioner yang disebar dengan menggunakan media google form oleh mahasiswa prodi akuntansi universitas muhammadiyah sidoarjo. Jumlah kuisioner yang diperoleh adalah 110 kuisioner. Akantetapi dalam analisis data, terdapat 10 data responden merupakan data outlier sehingga tidak dipakai dalam model penelitian.

TABEL 2: Uji Deskripsi Responden

\begin{tabular}{lcc}
\hline \multicolumn{1}{c}{ Keterangan } & Jumlah & $\%$ \\
\hline $\begin{array}{l}\text { Kuesioner yang } \\
\text { didistribusikan }\end{array}$ & 110 & $100 \%$ \\
\hline Kuesioner yang kembali & 110 & $100 \%$ \\
\hline $\begin{array}{l}\text { Kuesioner yang tidak bisa } \\
\text { digunakan }\end{array}$ & 10 & $9,09 \%$ \\
\hline $\begin{array}{l}\text { Jumlah Kuesioner yang bisa } \\
\text { digunakan }\end{array}$ & 100 & $90,91 \%$ \\
\hline
\end{tabular}

Sumber: Data primer yang diolah (2020)

\section{Uji Kualitas}

Penelitian ini menggunakan metode analisis SmartPLS versi 3 mulai dari outer model, inner model dan pengujian hipotesis. Model outer model digunakan dalam melakukan pengujian validity dan reliability.

\section{Pengujian Validitas}

pengujian validitas dilaksanakan dengan Convergent validity dan discriminant validity. Convergent validity bisa dikatakan valid jika mempunyai nilai AVE diatas 0,5 atau menunjukkan seluruh outer loading dimensi variabel mempunyai nilai loading > 0,5. Sedangkan Sedangkan Discrimant validity diukur berdasarkan pada crossloading pengukuran dengan konstruks tertentu.

Tabel 3 Hasil Uji Validitas (outer model) Pertama

\begin{tabular}{|c|c|c|c|c|}
\hline $\begin{array}{l}\text { Measurem } \\
\text { ent Model }\end{array}$ & \multicolumn{2}{|c|}{ Hasil } & \multirow{2}{*}{$\begin{array}{c}\text { Nilai } \\
\text { Kriti } \\
\text { \$. }\end{array}$} & \multirow{2}{*}{$\begin{array}{l}\text { Evalua } \\
\text { si } \\
\text { Model }\end{array}$} \\
\hline $\begin{array}{c}\text { Convergent } \\
\text { Validity }\end{array}$ & $\begin{array}{c}\text { Variabe } \\
1\end{array}$ & $A V E$ & & \\
\hline & $\mathrm{X} 1$ & 0.684 & $>0.5$ & Valid \\
\hline & Y1 & 0.587 & $>0.5$ & Valid \\
\hline & $\mathrm{Y} 2$ & 0.651 & $>0.5$ & Valid \\
\hline \multirow[t]{13}{*}{$\begin{array}{l}\text { Discrimina } \\
\text { nt Validity }\end{array}$} & $\begin{array}{l}\text { Indikat } \\
\text { or }\end{array}$ & $\begin{array}{c}\text { Cross } \\
\text { Loadi } \\
\text { ng }\end{array}$ & & \\
\hline & $\mathrm{X} 1.1$ & 0.862 & $>0.5$ & Valid \\
\hline & $\mathrm{X} 1.2$ & 0.808 & $>0.5$ & Valid \\
\hline & $\mathrm{X} 1.3$ & 0.810 & $>0.5$ & Valid \\
\hline & Y1.1 & 0.930 & $>0.5$ & Valid \\
\hline & $\mathrm{Y} 1.2$ & -0.228 & $>0.5$ & $\begin{array}{l}\text { Tidak } \\
\text { Valid }\end{array}$ \\
\hline & Y1.3 & 0.768 & $>0.5$ & Valid \\
\hline & Y1.4 & 0.919 & $>0.5$ & Valid \\
\hline & $\mathrm{Y} 2.1$ & 0.839 & $>0.5$ & Valid \\
\hline & $\mathrm{Y} 2.2$ & 0.809 & $>0.5$ & Valid \\
\hline & $\mathrm{Y} 2.3$ & 0.762 & $>0.5$ & Valid \\
\hline & $\mathrm{Y} 2.4$ & 0.820 & $>0.5$ & Valid \\
\hline & Y2.5 & 0.801 & $>0.5$ & Valid \\
\hline
\end{tabular}

Sumber : data primer yang diolah (2020)

Berdasarkan tabel 3 berdasarkan pengukuran dari data outer loading diperoleh 1 indikator yang tidak sesuai kriteria dan dinyatakan tidak valid. Indikator tersebut 
adalah indikator Y1.2 yakni kompetensi kepribadian. Untuk melakukan koreksi terhadap indikator-indikator tersebut agar sesuai dengan kriteria, maka indikator tersebut harus dikelurkan dan tidak diikutkan pada uji berikutnya dengan maksud untuk meningkatkan skor outer loadingnya.

Tabel 4 Hasil Uji Validitas (outer model) Kedua

\begin{tabular}{|c|c|c|c|c|}
\hline $\begin{array}{l}\text { Measurem } \\
\text { ent Model }\end{array}$ & \multicolumn{2}{|c|}{ Hasil } & \multirow{2}{*}{$\begin{array}{c}\text { Nilai } \\
\text { Kriti } \\
\text { \$. }\end{array}$} & \multirow{2}{*}{$\begin{array}{l}\text { Evalua } \\
\text { si } \\
\text { Model }\end{array}$} \\
\hline $\begin{array}{c}\text { Convergent } \\
\text { Validity }\end{array}$ & $\begin{array}{c}\text { Variabe } \\
1\end{array}$ & $A V E$ & & \\
\hline & $\mathrm{X} 1$ & 0.684 & $>0.5$ & Valid \\
\hline & Y1 & 0.768 & $>0.5$ & Valid \\
\hline & $\mathrm{Y} 2$ & 0.651 & $>0.5$ & Valid \\
\hline $\begin{array}{l}\text { Discrimina } \\
\text { nt Validity }\end{array}$ & $\begin{array}{c}\text { Indikat } \\
\text { or }\end{array}$ & $\begin{array}{c}\text { Cross } \\
\text { Loadi } \\
\text { ng }\end{array}$ & & \\
\hline & $\mathrm{X} 1.1$ & 0.862 & $>0.5$ & Valid \\
\hline & $\mathrm{X} 1.2$ & 0.809 & $>0.5$ & Valid \\
\hline & $\mathrm{X} 1.3$ & 0.809 & $>0.5$ & Valid \\
\hline & Y1.1 & 0.935 & $>0.5$ & Valid \\
\hline & Y1.3 & 0.764 & $>0.5$ & Valid \\
\hline & Y1.4 & 0.919 & $>0.5$ & Valid \\
\hline & $\mathrm{Y} 2.1$ & 0.840 & $>0.5$ & Valid \\
\hline & $\mathrm{Y} 2.2$ & 0.809 & $>0.5$ & Valid \\
\hline & $\mathrm{Y} 2.3$ & 0.762 & $>0.5$ & Valid \\
\hline & Y 2.4 & 0.820 & $>0.5$ & Valid \\
\hline & $\mathrm{Y} 2.5$ & 0.801 & $>0.5$ & Valid \\
\hline
\end{tabular}

Sumber : data primer yang diolah (2020)

Berdasarkan Tabel 4 berdasarkan pengukuran outer loading memperlihatkan bahwa seluruh indicator sesuai dengan kriteria dan dikatakan valid.

\section{Uji Reliabilitas}

Uji reliablitas bisa dilihat dari nilai composite reliability dan value dari Crombach's alpha nya, berikut hasil uji reliabilitasnya berikut ini:

Tabel 5 Hasil Uji Realibilitas (Composite Realibility)

\begin{tabular}{cccc}
\hline Yariabel & $\begin{array}{c}\text { Composite } \\
\text { Reliability }\end{array}$ & $\begin{array}{c}\text { Nilai } \\
\text { Kritis }\end{array}$ & $\begin{array}{c}\text { Evaluasi } \\
\text { Model }\end{array}$ \\
\hline $\mathrm{X} 1$ & 0.866 & $>0.7$ & Reliabel \\
\hline Y1 & 0.908 & $>0.7$ & Reliabel \\
\hline Y2 & 0.903 & $>0.7$ & Reliabel \\
\hline Sumber data diolah (2020) & &
\end{tabular}

Berdasarkan tabel 4.3 melalui pengukuran dari data nilai composite reliability seluruh indikator dapat memenuhi kriteria sehingga dinyatakan reliabel. Pengujian reliabilitas juga menggunakan rumus Crombach's alpha, dengan tujuan untuk mengetahui Kriteria instrumen penelitian dinayatakan reliabel, yaitu jika reliabilitas instrumen (r) hitung lebih besar dari $6(\geq 0,6)$.

Tabel 6 Hasil Uji Realibilitas (Crombach's alpha)

\begin{tabular}{cccc}
\hline Variabel & $\begin{array}{c}\text { Crombach's } \\
\text { alpha }\end{array}$ & $\begin{array}{c}\text { Nilai } \\
\text { Kritis }\end{array}$ & $\begin{array}{c}\text { Evaluasi } \\
\text { Model }\end{array}$ \\
\hline X1 & 0.769 & $>0.6$ & Reliabel \\
\hline Y1 & 0.844 & $>0.6$ & Reliabel \\
\hline Y2 & 0.866 & $>0.6$ & Reliabel \\
\hline
\end{tabular}

Sumber; data diolah (2020)

Berdasarkan tabel 6 melalui pengukuran dari data nilai Crombach's alpha seluruh indikator dapat memenuhi kriteria sehingga dinyatakan reliabel. Model analisis persamaan struktural yang dibuat dalam penelitian ini setelah dilakukan Calculate PLS Algorithm bisa dilihat melalui gambar berikut ini: 


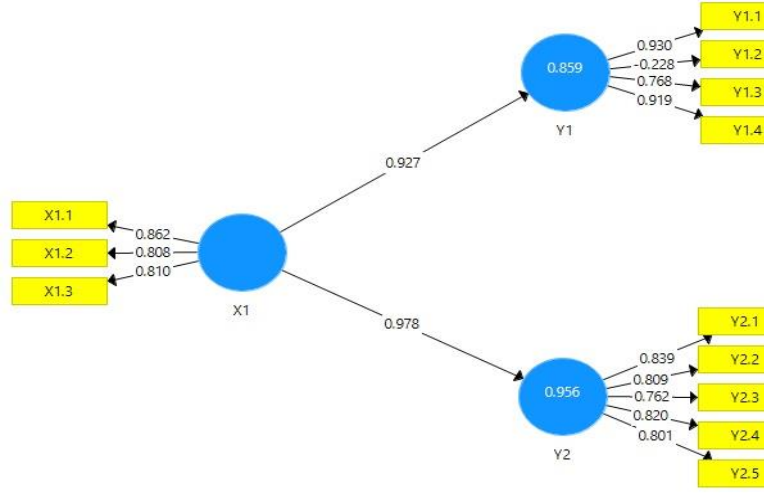

Gambar 1 Konstruksi Diagram Jalur Hasil Permodelan PLS

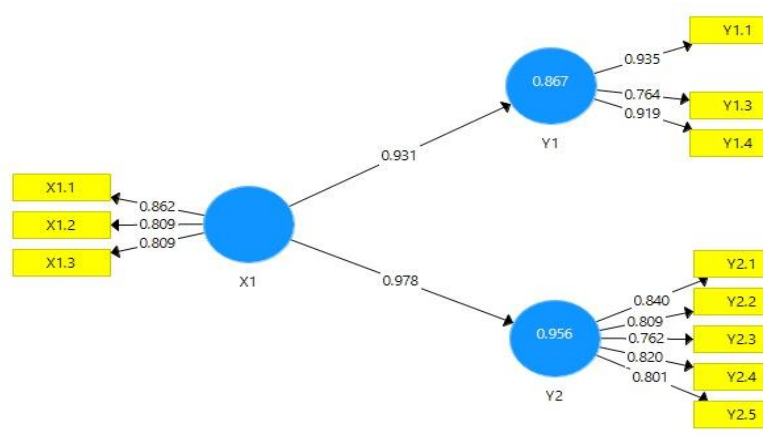

Gambar 2: Konstruksi Diagram Jalur Hasil

Permodelan PLS Setelah Modifikasi Model

\section{Pengujian Inner Model}

Inner model bisa juga disebut sebagai structural model yang mendeskripsikan hubungan atau keterkaitan antara variabel laten. Inner model dilakukan dengan pengevaluasian penggunaan R-Square Value yang merupakan bentuk dari uji goodness-fit (dependent variable) untuk memperlihatkan koefisien determinasi, Berikut nilai R-square variabel laten endogen dalam suatu model struktural jika sebesar Baik $(0,67)$, Moderat $(0,33)$ dan Lemah $(0,19)$.

TABEL 7 Nilai R-Square

\begin{tabular}{cc}
\hline Variabel & R-Square \\
\hline $\mathrm{Y}_{1}$ & 0.867 \\
\hline $\mathrm{Y}_{2}$ & 0.956 \\
\hline Sumber : Data diolah (2020) &
\end{tabular}

Nilai $\mathrm{R}$ Square untuk variabel Kompetensi Dosen $\left(\mathrm{Y}_{1}\right)$ sebesar 0,867 yang mempunyai makna bahwa Kompetensi Dosen $\left(\mathrm{Y}_{1}\right)$ dapat dijelaskan oleh Dampak Perubahan PSAK $\left(\mathrm{X}_{1}\right)$ sebesar $86,7 \%$ atau mempunyai pengaruh Baik sedangkan 13,3\% dideskripsikan variabel lain. Value dari RSquare untuk variabel Tingkat Pemahaman Mahasiswa $\left(\mathrm{Y}_{2}\right)$ sebesar 0,956 yang mempunyai makna bahwa Tingkat Pemahaman Mahasiswa dapat dideskripsikan Dampak Perubahan PSAK $\left(\mathrm{X}_{1}\right)$ sebesar 95,6\% atau memiliki pengaruh "Baik sedangkan $4,4 \%$ dijelaskan variabel lain diluar yang telah diteliti.

Penilaian Goodness of fit dapat terlihat dari value $\mathrm{Q}^{2}$. Dari Tabel 1 dapat ditentukan nilai $\mathrm{Q}^{2}$ sebagai berikut:

$$
\begin{aligned}
\mathrm{Q}^{2} & =1-\left(1-\mathrm{R} 1^{2}\right)\left(1-\mathrm{R} 2^{2}\right) \\
& =1-(1-0,867)(1-0,956) \\
& =1-(0,133)(0,044) \\
& =1-0,089 \\
& =0,91
\end{aligned}
$$

Dari hasil perhitungan diatas dapat diketahui bahwa nilai $\mathrm{Q}^{2}$ sebesar 0,91. Nilai $\mathrm{Q}^{2}>0$, maknanya bahwa model penelitian dalam penelitian ini mempunyai predictive relevance, sehingga layak untuk dilaksanakan analisis selanjutnya.

\section{PEMBAHASAN}

\section{Pengujian Hipotesis}

Uji Hipotesis dilaksanakan dengan melakukan uji t statistic, dengan tujuan untuk melakukan pengujian keterkaitan atau hubungan. Apakah variabel independen secara parsial memiliki pengaruh atau tidak memiliki pengaruh terhadap variabel dependen? pengujian hipotesis mengacu pada tingkat signifikansi yang telah ditetapkan yakni $95 \%(\alpha=0.05)$. Tingkat signifikansi t tabel value adalah 95\% (1,96). Tingkat signifikansi hipotesis dapat diukur dengan 
melakukan perbandingan antara nilai $\mathrm{t}$ table dan t statisticnya. Apabila t statistic $>$ nilai $\mathrm{t}$ table $(1,96)$ dengan tingkat signifikansi $\alpha=0.05$, berarti hipotesis diterima atau nilai estimasi jalur dikatakan signifikan. Pada SmartPLS 3 untuk mendapatkan output uji hipotesis dilaksanakan dengan bootsrapping, Berikut adalah output uji t statistic:

TABEL 8: Hasil Uji T-Statistic

\begin{tabular}{cccccc}
\hline Hipotesis & $\begin{array}{c}\text { Original } \\
\text { Sample } \\
(\mathrm{O})\end{array}$ & $\begin{array}{c}\text { Sample } \\
\text { Mean } \\
(\mathrm{M})\end{array}$ & $\begin{array}{c}\text { Standard } \\
\text { Deviation } \\
(\mathrm{STDEV})\end{array}$ & $\begin{array}{c}\text { T Statistic } \\
(\text { IO/STDEVI) }\end{array}$ & $\begin{array}{c}\mathrm{P} \\
\text { Values }\end{array}$ \\
\hline $\mathrm{X}_{1}->\mathrm{Y}_{1}$ & 0.927 & 0.927 & 0.016 & 59.730 & 0.000 \\
\hline $\mathrm{X}_{1}->\mathrm{Y}_{2}$ & 0.978 & 0.977 & 0.007 & 130.700 & 0.000 \\
\hline
\end{tabular}

Sumber : Data diolah (2020)

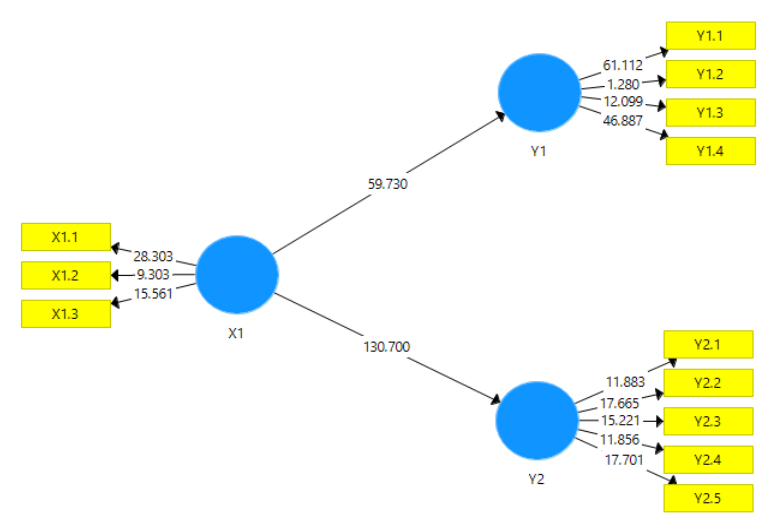

Gambar 3 Konstruksi Diagram Jalur Hasil Permodelan PLS Bootstrapping

Berdasarkan Gambar 3 di atas maka bisa dideskripsikan hasil uji hipotesis dalam penelitian ini, antara lain:

Hipotesis pertama diterima, Berdasarkan Hasil t-statistik $\mathrm{X}_{1} \rightarrow \mathrm{Y}_{1}$ mempunyai nilai $t$ statistic sebesar 59.730 menunjukkan bahwa value $\mathrm{t}$ statistic lebih besar dari t tabel sebesar 1,96 dengan tingkat signifikansi 0.000 , maknanya $\mathrm{H}_{1}$ diterima atau terdapat pengaruh positif antara Dampak Perubahan PSAK $\left(\mathrm{X}_{1}\right)$ terhadap Kompetensi Dosen $\left(\mathrm{Y}_{1}\right)$, dimana kompetensi pedagogik merupakan indikator yang memberikan pengaruh paling besar dengan nilai 61,112 .
Hipotesis kedua juga diterima Hasil tstatistik $\mathrm{X}_{1} \rightarrow \mathrm{Y}_{2}$ memiliki nilai $\mathrm{t}$ statistic sebesar 130.700 menunjukkan bahwa nilai $\mathrm{t}$ statistic > dari t tabel sebesar 1,96 dengan tingkat signifikansi 0.000 maknanya $\mathrm{H}_{2}$ diterima atau terdapat pengaruh positif antara Dampak Perubahan PSAK $\left(\mathrm{X}_{1}\right)$ terhadap Tingkat Pemahaman Mahasiswa $\left(\mathrm{Y}_{2}\right)$. Dimana Tahap pencatatan merupakan indikator yang memberikan pengaruh paling besar dengan nilai 17,701 . Hal tersebut menunjukkan bahwa seluruh tahapan dalam siklus akuntansi sangat penting, akantetapi yang paling menentukan tingkat pemahaman mahasiswa adalah basic dalam tahapan pencatatan yang menjadi dasar untuk tahapan siklus akuntansi selanjutnya.

Hasil penelitian diatas didukung dengan penelitian sebelumnya yakni Heykal et al (2014), Poudel et al (2014) dan Nurunnabi (2014) yang menyatakan bahwa dampak perubahan standar ternyata berpengaruh terhadap sektor pendidikan dalam hal ini adalah kompetensi dosen dan tingkat pemahaman mahasiswa. Dimana level (tingkat) pendidikan juga mempengaruhi proses perkembangannya. Hal serupa juga dinyatakan oleh Zeghal dan Mhedhbi (2006) bahwa dengan adanya perubahan standar seharusnya menjadi perhatian lebih bagi para mahasiswa akuntansi dan akuntan pendidik (dosen). Hal tersebut dilakukan dengan tujuan untuk mendukung materi pembelajaran yang singkron dengan dunia kerja dan juga untuk mendukung peningkatan pengetahuan mengenai perubahan standar yakni PSAK terbaru, PSAK amandemen dan PSAK revisi.

Hal serupa juga dinyatakan Bastian (2011) yang mengungkapkan bahwa perubahan standar memberikan pengaruh besar pada perkembangan akuntansi di berbagai negara meliputi praktik di berbargai sektor salah satunya adalah dunia pendidikan. Sedangkan Pulungan (2013) juga menyatakan Dampak perubahan PSAK merupakan tantangan dalam dunia akademik dan memberikan pengaruh terhadap peningkatan kompetensi dosen dan tingkat pemahaman mahasiswa akuntansi di Indonesia. 


\section{KESIMPULAN}

Berdasarkan dari hasil analisis dan pembahasan terkait dampak perubahan PSAK di Prodi Akuntansi Universitas Muhammadiyah Sidoarjo bisa diambil kesimpulan sebagai berikut:

1. Kompetensi dosen dalam pembelajaran PSAK berbasis IFRS dipengaruhi oleh dampak perubahan PSAK, kompetensi pedagogik merupakan indikator yang memberikan pengaruh paling besar.

2. Tingkat Pemahaman Mahasiswa dipengaruhi oleh dampak perubahan PSAK, Tahap pencatatan merupakan indikator yang memberikan pengaruh paling besar. Maknanya seluruh tahapan dalam siklus akuntansi sangat penting, akantetapi yang paling menentukan tingkat pemahaman mahasiswa adalah basic dalam tahapan pencatatan yang menjadi dasar untuk tahapan siklus akuntansi selanjutnya.

Berdasarkan kesimpulan yang telah diuraikan sebelumnya, maka dapat diberikan saran berikut ini:

1. Indikator yang telah ditentukan sebagai butir-butir pertanyaan pada masingmasing variabel agar dibuat dengan lebih detail lagi dan disesuaikan kembali.

2. Perlunya dilakukan penelitian lebih lanjut terkait dampak-dampak lain yang dapat berpengaruh terhadap kompetensi dosen dan tingkat pemahaman mahasiswa.

\section{DAFTAR PUSTAKA}

Ankarath, Nandakumar. 2012. Memahami IFRS: Standar Pelaporan Keuangan Internasional. Alih Bahasa: Priyo Darmawan. PT Indeks: Jakarta.

Bastian, Indra. 2011. Minim, Pemahaman Akuntan Terhadap Standar Akuntansi Internasional. https://feb.ugm.ac.id/id/berita/408mahasiswa-ugm-di-adelaide.html. Diakses tanggal 10 April 2020 (10:31)

Budhiyanto, Suryanti J. \& Nugroho, Ika P. 2004. "Pengaruh Kecerdasan Emosional terhadap Tingkat Pemahaman Akuntansi”. Jurnal
Ekonomi Bisnis, Vol. X, No.2, Hal.260-281

Christiani,Yuningsih Nita, 2015, Pemahaman Mahasiswa Akuntansi Terhadap International Financial Reporting Standar (IFRS), Tesis. Universitas Kristen Satya Wacana. Salatiga

Cooper, Donal R and Scindler, Pamela S (2006). Busines Research Methods. The MC Grow-Hill Lumpanies: Singapore.

Efritania. 2014. Tingkat Pengetahuan Mahasiswa S1 Akuntansi Terhadap Perubahan PSAK. Universitas Negeri Surabaya, Surabaya.

Gustiani dan Marsudi.2018. Pengaruh Minat Belajar Ketersediaan Sarana Pendidikan Dan Kompetensi Dosen Terhadap Pemahaman Psak Konvergensi. Jurnal Akunida ISSN 2442-3033 Volume 4 Nomor 1, Juni 2008. Universitas Djuanda.

Heykal et al. 2014. Impact Analysis of Indonesian Financial Accounting Standard based on the IFRS Implementation for Financial Instruments in the Indonesian Commercial Bank. 2nd World Conference on Business. pages 12471250 .

Kieso dan Weygandt.2011.Intermediate Accounting edisi tahun 2011. Jakarta: Erlangga.

Mahendra, Reza, 2013, Dampak Konvergensi PSAK ke IFRS Terhadap Arus Kas Pada PT Rimo Catur Lestari Tbk Periode 2010-2011 Dalam Pengambilan Keputusan Investasi, Penulisan Ilmiah, Program Studi Stara Satu Manajemen Program Pasca Setara Sarjana Muda, Unversitas Gunadarma, Depok.

Martani, Dwi. 2019. Overview Perkembangan Standar Akuntansi. https://staff.blog.ui.ac.id/martani/files/20 19/01/Overview-Perkembangan-Standar24012019.pdf. 16. April 2020 (09.00) 
Nurunnabi, M. 2014. The impact of cultural factors on the implementation of global accounting standards (IFRS) in a developing country. Advances in Accounting, incorporating Advances in International Accounting.

Poudel, G., A. Hellman, H. Perera. 2014. The adoption of International Financial Reporting Standards in a noncolonized developing country: The case of Nepal. Advances in Accounting, incorporating Advances in International Accounting. pages 209-216.

Pulungan. 2013. Persepsi Mahasiswa Terhadap IFRS dan Kompetensi Mahasiswa dalam Memahami dan Mengaplikasikan IFRS. Jurnal Akuntansi dan Manajemen Jilid 8 Terbitan 1 29-38. Politeknik Negeri Malang.

Saretta. 2019. Pentingnya Memahami PSAK (Pernyataan Standar Akuntansi Keuangan). https://www.cermati.com/artikel/penting nya-memahami-psak-pernyataan-standarakuntansi-keuangan. 15 April 2020. 09.39

Sugiyono. 2013. Metode Penelitian Bisnis (Pendekatan Kuantitatif Kualitatif, dan R\&D), Alfabeta. Bandung.
Undang-Undang Republik Indonesia, 2005, Tentang Guru dan Dosen. http://sindikker.dikti.go.id. Diakses pada 03 Maret 2017 pukul 20.24

Utami,Nadhia Riesthi Putri,2012, Pengaruh Status Perguruan Tinggi, Status Mahasiswa, Kecerdasan Emosional, dan Persepsi Mahasiswa Mengenai Kompetensi Dosen Terhadap Pemahaman IFRS Pada Mahasiswa Akuntansi Kota Semarang, Skripsi, Universitas Diponogoro, Semarang.

Wahyuni, Ersa Tri. 2020. Overview PSAK Terbaru dan SAK Outlook 2020. https://iaijawatimur.or.id/storage/app/upl oads/public/5e3/ce3/c07/5e3ce3c078ad30 61862307.pdf. 25 Maret 2020 (10.07)

Wahyuni, Nurseffi Dwi. 2009. Konvergensi IFRS Berlaku 2012. http://finance.detik.com. 16 April 2020 (10:35).

Wibowo, 2007, Manajemen Kinerja, PT. Raja Grafindo Persada. Jakarta.

Zeghal, D., \& Mhedhbi, K. (2006). An analysis of the factors affecting the adoption of international accounting standards by developing countries. The International Journal of Accounting, 41, 373-386. https://doi.org/10.1016/j.intacc.2006.09.0 09. 